\title{
As orientações para o ensino de diferentes tipos de letras nas cartilhas ¿Quieres leer? (Uruguai) e Queres ler? (RS, Brasil)
}

\author{
Las orientaciones para la enseñanza de diferentes tipos de letras en las \\ cartillas ¿Quieres leer? (Uruguay) y Queres ler? (RS, Brasil)
}

\author{
Guidelines for teaching different handwriting styles in the textbooks \\ ¿Quieres leer? (Uruguay) and Queres ler? (RS, Brazil)
}

\author{
Alessandra Amaral da Silveira ${ }^{1}$ \\ Caroline Braga Michel $^{2}$ \\ Eliane Peres ${ }^{3}$
}

\begin{abstract}
Resumo
Tem-se como objetivo principal neste trabalho cotejar as orientações apresentadas aos professores sobre o ensino da escrita, enfatizando os tipos de letras presentes na obra didática uruguaia ¿Quieres Leer?, de José Henriques Figueira, e na adaptação Queres Ler?, feita por Olga Acauan e Branca Diva Pereira de Souza. Trata-se de uma obra utilizada para o ensino da leitura e da escrita cujo método era caracterizado como "intuitivo analíticosintético de leitura e escrita corrente de palavras e frases básicas ou normais" e que foi adaptada pelas duas professoras gaúchas mencionadas para uso nas aulas públicas do Rio Grande do Sul no século XX, imediatamente após a missão de estudos realizada ao Uruguai, em 1914. Para tanto, analisaram-se três exemplares: duas edições uruguaias $(1905 ; 1931)$ e uma edição gaúcha (1929). As análises pautaram-se nos trabalhos de Faria Filho (1998), Vidal e Gvirtz (1998), Vidal e Esteves (2003), Peres (2003), Fetter, Lima e Lima (2010) e possibilitam observar que a versão uruguaia ressaltava, nas "Notas gerais" e nas "Notas explicativas", existentes desde as primeiras lições, a importância de exercícios musculares básicos, preparatórios para a escrita, inclusive reproduzindo, juntamente com as notas, o movimento que deveria ser realizado no exercício. Essa orientação, no entanto, foi suprimida na versão gaúcha, a Queres Ler?, o que indica uma diferença entre a versão uruguaia e a edição gaúcha no que tange à maneira como os/as professores/as deveriam conduzir o processo inicial do ensino da escrita.
\end{abstract}

Palavras-Chave: ensino da escrita; tipos de letras; Queres Ler?; Rio Grande do Sul.

\section{Resumen}

Se tiene como objetivo principal en este trabajo cotejar las orientaciones presentadas a los profesores sobre la enseñanza de la escritura, com énfasis en los los tipos de letras presentes en la obra didáctica uruguaya ¿Quieres Leer?, de José Henriques Figueira, y en la adaptación Queres Ler?, hecha por Olga Acauan y Blanca Diva Pereira de Souza. Se trata de una obra usada para la enseñanza de la lectura y de la escritura cuyo método fue caracterizado como "intuitivo analítico-sintético de lectura y escritura corriente de palabras y frases básicas o normales" y que fue adaptado por las dos profesoras gauchas mencionadas para uso en las clases públicas de Rio Grande do Sul en el siglo XX, inmediatamente después de la misión de estudios realizada en Uruguay, en 1914. Para ello, se analizaron tres ejemplares: dos ediciones uruguayas $(1905,1931)$ y una edición gaucha (1929). Los análisis se basó en los trabajos de Faria Filho (1998), Vidal y Gvirtz (1998), Vidal y Esteves (2003), Peres

\footnotetext{
${ }^{1}$ Mestre em Educação em Ciências: química da vida e saúde; Universidade Federal de Pelotas - UFPel; Pelotas, RS, Brasil; ale82amaral@yahoo.com.br.

${ }^{2}$ Doutora em Educação. Universidade Federal de Pelotas - UFPel; Pelotas, RS, Brasil; caroli_brga@yahoo.com.br.

${ }^{3}$ Doutora em Educação. Universidade Federal de Pelotas - UFPel; Pelotas, RS, Brasil; eteperes@ gmail.com.
} 
(2003), Fetter, Lima y Lima (2010) y posibilitan observar que la versión uruguaya resaltaba, en las "Notas generales" y en las "Notas explicativas", desde las primeras lecciones, la importancia de ejercicios musculares básicos, preparatorios para la escritura, incluso reproduciendo, junto con las notas, el movimiento que debía realizarse en el ejercicio. Esta orientación, sin embargo, fue suprimida en la versión gaúcha, a Queres Ler?, lo que indica una diferencia entre la versión uruguaya y la edición gaúcha en lo que se refiere a la manera como los/as profesores/as debían conducir el proceso inicial de la enseñanza de la escritura.

Palabras claves: enseñanza de la escritura; tipos de letras; Queres Ler?; Rio Grande do Sul.

\begin{abstract}
This study is aimed to compare the guidelines for handwriting teaching by emphasizing the different types of writing as presented to teachers in the Uruguayan textbook ¿Quieres Leer?, by José Henriques Figueira, and in the Brazilian edition Queres Ler?, by Olga Acauan and Branca Diva Pereira de Souza. This book was used to teach writing and reading, and its method was characterized as "analytic-synthetic intuitive for the current reading and writing of basic or regular words and phrases". It was adapted by the above-mentioned Brazilian teachers in order to use in the public schools of the State of Rio Grande do Sul (RS), southern Brazil, in the twentieth century, right after a study mission carried out in Uruguay in 1914. Therefore, three samples were analyzed: two Uruguayan editions $(1905 ; 1931)$ and one Brazilian edition (1929). Based on Faria Filho (1998), Vidal \& Gvirtz (1998), Vidal \& Esteves (2003), Peres (2003), and Fetter, Lima \& Lima (2010), this study made possible to observe that in the Uruguayan version the importance of preparatory basic muscle exercises for writing was highlighted in both "General Notes" and "Explanatory Notes" since de first lessons, including the movements to be performed in each exercise. However, this guideline was deleted in the Brazilian edition, Queres Ler?, which may be seen as an indication of a difference between the Uruguayan and the Brazilian editions in terms of how the teachers should conduct the initial process in handwriting teaching.
\end{abstract}

Keywords: handwriting teaching; handwriting styles; Queres Ler?; Rio Grande do Sul

\title{
1. Introdução
}

No final do século XIX, assim como nas primeiras décadas do século XX, havia uma prática por parte das autoridades brasileiras de enviar missões educacionais ao estrangeiro com a finalidade de identificar os métodos de ensino e os avanços pedagógicos das nações tidas como referência (NÓVOA; SCHRIEWER, 2000). Conhecer, descrever, apropriar e (re) significar na prática o que foi observado e vivenciado nas realidades dos países e/ou Estados tidos como referência configurou-se nesse período, portanto, como uma estratégia importante para aqueles que almejavam promover mudanças em seus setores educacionais. Por isso, muitas vezes, essas viagens eram incentivadas e financiadas pelo poder público.

Não obstante dessa realidade mundial e nacional, as autoridades do Rio Grande do Sul, no esforço de qualificar e de (re) organizar o ensino público do estado que estava em fase de expansão e consolidação, enviaram à capital do Uruguai uma missão de estudos (ARRIADA; TAMBARA, 2013; MICHEL, 2017). Essa viagem ocorreu em dois momentos. No primeiro, concretizado no ano de 1913, um grupo (composto por dois professores e quatro 
professoras $)^{4}$ permaneceu três meses no Uruguai, e tinha como objetivo específico estudar os métodos de ensino adotados nas aulas públicas daquele país, bem como analisar tudo o que fosse relativo ao "importantíssimo ramo de serviço da instrução" ( $A$ FEDERAÇÃO, 1913, p. 5). O segundo momento da missão foi realizado no ano de 1914, sendo que participaram dessa viagem três estudantes recém formadas pela Escola Complementar de Porto Alegre e três professoras em exercício no magistério público primário do Rio Grande do $\mathrm{Sul}^{5}$. Vale ressaltar, contudo, que somente duas integrantes desse grupo, Branca Diva Pereira de Souza e Olga Acauan, concluíram seus estudos em Montevidéu no ano de 1916.

Decorrente dessa experiência e, possivelmente, impressionadas com a qualidade dos métodos e dos materiais pedagógicos da vizinha República, as duas professoras gaúchas mencionadas adaptaram, no final da segunda década do século XX, para uso nas escolas primárias do Rio Grande do Sul, o Primeiro Livro de Leitura ¿Quieres Leer?, do professor uruguaio José Henriques Figueira (PERES, 1999; MICHEL, 2018).

Estudos têm evidenciado, entre outros aspectos, que Queres Ler? marcou um período de escolarização e do ensino, apresentando um novo método de leitura e de escrita no cenário gaúcho a partir dos anos 20 do século XX, bem como identifica uma geração de professoras e de alunos das escolas gaúchas dos anos 1920-1930 (PERES, 1999; TRINDADE, 2001). Compreendendo, portanto, a relevância e o uso dessa cartilha por um longo período, tanto no Rio Grande do Sul quanto no Uruguai, este trabalho tem como objetivo principal cotejar as orientações sobre o ensino da escrita na fase inicial da escolarização, enfatizando os tipos de letras apresentadas aos/às professores/as na obra didática uruguaia ¿Quieres Leer? e na adaptação Queres Ler?.

A escolha em analisar as orientações sobre o ensino da escrita na fase inicial da escolarização focando nos tipos de letras ocorreu pelo interesse em dar continuidade a outros estudos que vêm sendo desenvolvidos ${ }^{6}$ e pela relevância da temática à época. Destaca-se nesse sentido que:

[...] o ensino da escrita ocupa um lugar bastante importante na pedagogia principalmente por facilitar a leitura, porque nós já vimos que o método de leitura se apoia quási que exclusivamente na escrita.

\footnotetext{
${ }^{4}$ Affonso Guerreiro Lima, Ondina Godoy Gomes, Georgina Gomes Moritz, Marieta de Freitas Chaves e Florinda Tubino Sampaio foram liderados pelo diretor da Escola Complementar de Porto Alegre/RS Alfredo Clemente Pinto.

${ }^{5}$ Carlina Carneiro Cunha, Marina Barreto Cunha, Olga Acauan, Branca Diva Pereira de Souza, Maria Idalina Mariante Pinto e Maria José de Souza Cunha.

${ }^{6}$ Os estudos que encontram-se em desenvolvimento a esse respeito são: (i) Tese em andamento intitulada Cultura Gráfica Escolar: uma pesquisa em cadernos de alunos em fase inicial de escolarização (1937-2015) e (ii) Projeto de Pós-doutorado Junior financiado pelo Cnpq (Processo 167676/2017-2) sobre a circulação e adoção da cartilha Queres Ler? no Rio Grande do Sul.
} 
O que é escrever bem - Escrever bem é escrever legivelmente, sem borrões, com rapidez e, se puder ser, com elegância. (FIGUEIRINHAS, 1927, p. 301-302).

Como se observa no excerto retirado do Manual Lições de Pedagogia, a discussão sobre o ensino da escrita era algo presente tanto nos livros escolares destinados aos estudantes em fase inicial da escolarização como nos manuais produzidos para uso dos professores e das professoras $^{7}$. Além disso, se identifica que a discussão era pautada não só no método mais adequado para o ensino da escrita, mas também pelos modos e modelos de escrita que deveriam ser seguidos e desenvolvidos nos primeiros anos de escolarização para o "escrever bem", o qual era caracterizado pela escrita clara, legível e rápida.

Desse modo, considerando que os artefatos da cultura material escolar apresentam instruções e orientações sobre o ensino da escrita, optamos por analisar uma obra didática que, como já referido, teve significativa circulação e uso nas escolas públicas gaúchas no século XX. Para tanto, ao todo, foram analisados três exemplares do título ¿Quieres Leer?, sendo duas edições uruguaias $(1905 ; 1931)$ e uma versão gaúcha (1929). A opção por dois exemplares uruguaios e uma edição gaúcha ocorreu em virtude de termos observado mudanças significativas entre as versões publicadas no Uruguai, diferentemente das edições gaúchas que não apresentam modificações entre si.

Assim, destacamos que este texto está organizado em duas seções. Na primeira, realizamos uma discussão acerca da proposta e da estrutura das cartilhas ¿Quieres Leer? e Queres Ler? e na segunda apresentamos as orientações para o ensino da escrita, com ênfase sobre os diferentes tipos de letras a serem ensinados e os modelos caligráficos que estavam em discussão na época.

\section{As cartilhas ¿Quieres Leer? e Queres Ler?: proposta e estrutura}

A obra Quieres Leer?, de autoria de José Henriques Figueira, foi publicada no Uruguai no ano de 1892, sendo, contudo, incorporada oficialmente na lista de textos escolares desse país no ano de 1901, durante a administração do Dr. Abel J. Pérez ${ }^{8}$ (ZARILLI; SORIANO, 1946). A obra faz parte da Serie graduada de lecturas culturales básicas, composta de quatro cursos - preparatório, elementar, intermediário e superior - sendo ¿Quieres Leer? o primeiro livro de leitura da coleção, portanto, do curso preparatório. Ainda

\footnotetext{
${ }^{7}$ Conforme Bastos (2006), os manuais pedagógicos eram considerados instrumento produtores de saberes e de disseminação de conhecimentos pedagógicos. Eles eram também conhecidos como manuais de profissionalização destinados a professores em formação inicial ou continuada e "visam fundar práticas profissionais em conformidade com um modelo de forma prescritiva e útil" (BASTOS, 2006, p. 01).

${ }^{8}$ Abel J. Pérez foi Inspetor Nacional da Instrução Primária no Uruguai nas primeiras décadas do séc. XX. Como vocales de sua administração, foram nomeados José Piaggio, Juan Paullier, Carloz Vaz Ferreira e Mariano Pereira (ARAÚJO, 1911, p. 504).
} 
segundo os autores supracitados, uma das inovações que a obra trouxe para o período foi ensinar a escrita simultaneamente com a leitura.

Esse também foi um dos aspectos ressaltados pelo professor Antonio Henrique de Casaes (ex-docente de Pedagogia da Escola Complementar de Porto Alegre) em seu parecer enviado à Comissão de Exame de Obras Pedagógicas do Rio Grande do Sul no ano de 1924, para a aprovação do uso da adaptação da obra uruguaia, feita por Olga Acauan e por Branca Diva Pereira de Souza, nas escolas públicas gaúchas ${ }^{9}$. Apreende-se, assim, a partir da redação do parecer publicado no início da versão de Queres Leres? (1929), que a cartilha foi adotada não só pelo fato de ensinar as crianças a lerem e a escreverem em um curto período de tempo e de forma simultânea, mas também por apresentar uma didática diferenciada da que até então vinha sendo praticada nas escolas do Rio Grande do Sul: o anacronismo dos métodos $A B C^{10}$, a ausência de significado no ato de aprender a ler, o aborrecimento, a fadiga e a monotonia dos métodos, em especial o da soletração, que faziam uso apenas de letras e dos sons para o ensino da leitura.

Desse modo, há, no parecer, a ressalva de que a obra propunha aquilo que era considerado de mais moderno à época: ensino intuitivo, leitura de palavras e frases, diferenciando-se, portanto, da forma de ensinar a ler e a escrever corrente, o que, segundo os defensores da obra, representava uma maior qualidade para o ensino primário gaúcho. Conforme consta, a escrita era entendida pelo autor como algo "[...] más difícil que leer; porque para ello se requiere poder leer y, además, el adiestramiento (sinergia) de un centenar de pequeños y grandes músculos y muchas células y ramificaciones nerviosas (neuronas). (QUIERES LEER?, 1931, p. XIII) e a leitura era considerada na obra um "trabalho inteligente", uma "disciplina" que permitia adquirir a maior parte dos conhecimentos possíveis às pessoas. Elemento propulsor da oralidade, do enriquecimento do vocabulário, da prática da ortografia, a leitura é apresentada como indissociável da escrita. Logo, a leitura não

\footnotetext{
${ }^{9}$ É interessante ressaltar, como bem indicou o parecerista da obra, que o método defendido na Queres Ler? já vinha sendo usado no Rio Grande do Sul, especificamente, por meio da prática pedagógica de Branca Diva Pereira de Souza anteriormente a data de sua aprovação em 1924.. Não há a informação de quando este método começou a ser ministrado pela professora, contudo, há indícios de na imprensa gaúcha de que o método estava sendo colocado em prática já no ano de 1920. Apesar de ser explicitado na reportagem que estava sendo usado o método de ensino e não a cartilha, é provável que no ano de 1920 já estivesse em uso a versão impressa da mesma. Todavia, considerando que o Prólogo escrito pelo professor uruguaio é do ano de 1919 infere-se que uma primeira versão, ainda que não estivesse impressa, tenha sido produzida entre os anos de 1917 e 1919 para que o professor uruguaio pudesse realizar sua avaliação sobre a adaptação para o português e, então, emitir seu parecer (MICHEL, 2018).

10 "Consiste este velho, demorado e tedioso método em ensinar primeiro o nome de cada uma das vinte e seis letras, depois a combinação delas em sílabas sem sentido, de dois e três caracteres, mais tarde a sua junção em palavras de duas, três e mais sílabas. Da significação das palavras não se faz nenhum caso." (CALKINS, 1956, p. 408-409, grifo nosso).
} 
poderia ser um trabalho da memória. Não deveria, por isso, ser ensinada através de sons "que nada significam", de letras ou de sílabas (QUERES LER?, 1929). É possível evidenciar, assim, que a organização da obra tem como ponto de partida a palavra, associada à imagem e ao significado, no ensino da leitura e da escrita (PERES, 1999).

É possível indicar, dessa forma, que há, no primeiro livro ¿Quieres Leer?, a defesa da possibilidade de a leitura ser uma forma de interpretar os sentimentos e os pensamentos, e de atribuir significado e sentido à leitura. Essa maneira de aprender só poderia ser alcançada, portanto, através do emprego do método tido como mais adequado de ensino da leitura e da escrita: o método intuitivo analítico sintético de leitura e escrita corrente de palavras e frases básicas ou normais (QUERES LER?, 1929). Assim era denominado o método da obra: intuitivo, porque as "palavras normais ou básicas" representariam coisas que as crianças poderiam ver, tocar, apalpar, observar (QUERES LER?, 1929); também porque cada palavra apresentada correspondia a um objeto respectivo, supostamente do conhecimento das crianças, havendo, portanto, a associação entre as ideias e as palavras, levando a uma leitura compreensiva por parte do aprendiz (QUERES LER?, 1929). Essas características eram consideradas centrais no método intuitivo, uma vez que "observar significa progredir da percepção para a idéia, do concreto para o abstrato, dos sentidos para a inteligência, dos dados para o julgamento" (VALDEMARIM, 1998, p. 69).

Embora no livro adaptado por Olga Acauan e Branca Diva Pereira de Souza o parecerista Antonio Henrique de Casaes indique que a versão gaúcha "não representa uma simples traducção, mas uma adaptação criteriosa com grande numero de modificações, oriundas de acurado estudo e repetidas aplicações practicas, do excelente trabalho do notavel professor uruguaio [...]" (QUERES LER?, 1929, p. XI), foi possível evidenciar em trabalhos anteriores que as duas cartilhas seguem a mesma proposta e basicamente a mesma estrutura, apresentando pequenas variações, o que demonstra que a obra gaúcha seguiu os princípios pedagógicos de ¿Quieres Leer?, especialmente o princípio básico da gradação de dificuldades lexicográficas, ortográficas, fonéticas e prosódicas, apresentando uma dificuldade por vez (PERES, 1999; MICHEL; ARRIADA; PERES, 2015; MICHEL, 2017).

Assim, destaca-se que a proposta da obra foi organizada em ambas as versões respeitando a divisão de quatro partes, sendo as três primeiras constituídas por grupos de "palavras normais" e frases, e a quarta, por trechos literários (pequenos textos). Em cada uma das partes há uma classificação que obedece, como destacado, características lexicográficas, ortográficas, fonéticas e prosódicas. Na primeira parte, estudam-se as palavras de uma a quatro letras, monossílabas e dissílabas; acento grave; sílabas diretas e inversas; letras de 
figura simples e de som simples e duplo; letras minúsculas inglesas, itálicas e romanas; ponto final; vírgula e traço de união; frases com as dificuldades vencidas. Na segunda parte, palavras de até oito letras e três sílabas; acento agudo; sílabas de uma a três letras; articulações diretas e inversas simples e mistas; letras de dupla figura e de duplo som; letras maiúsculas inglesas, itálicas e romanas; sinais de interrogação; traço de união, ponto e vírgula e frases simples. Na terceira parte, palavras de até de onze letras e quatro sílabas; esdrúxulas; articulações diretas e inversas simples e compostas, mistas simples e compostas; ditongo; letras de som composto; trema; sinal de exclamação, dois pontos e frases simples. E, por fim, na quarta são trabalhados trechos literários, nos quais as principais temáticas abordadas são religião, higiene e comportamento.

Cada uma dessas partes é precedida por uma nota geral, de uma a duas páginas que orienta o trabalho docente, especialmente para o grupo de palavras que deveria ser estudado. Os mesmos estão distribuídos em lições nas quais são trabalhadas as dificuldades. Nas três versões analisadas, as lições são numeradas, e cada uma delas também apresenta uma nota explicativa que orienta o/a professor/a para o desenvolvimento das mesmas. Há, portanto, praticamente, uma nota por página nas cartilhas. É importante mencionar que foram nessas notas, gerais e explicativas, que foram localizadas as orientações sobre o ensino da escrita e dos diferentes tipos de letras que serão abordadas na seção seguinte.

Antes de iniciarmos essa discussão, cabe, todavia, salientar as especificidades que foram observadas em cada uma das três edições analisadas neste texto no que tange às suas estruturas. A ¿Quieres Leer? de 1905 apresenta além das quatro partes precedidas por uma nota geral, uma seção, ao final da cartilha, intitulada Instrucciones para el acertado empleo del Libro primero de lectura, na qual são explicitadas as compreensões teóricas de como se aprende a ler, de como se deve ensinar a ler e o "passo a passo" para desenvolver cada lição do livro. Essas orientações não são apresentadas na edição de 1931. Ao invés delas, há, nesse exemplar, a reprodução de um vocabulário básico, graduado em três séries, que "contiene más de mil palavras de uso diário, para el ejercicios de ideo visualización, pronunciación y lexicografia [...] Estos vacabularios se usarán también para 'tests”” (¿QUIERES LEER?, 1931, p. 136). E, ainda, ao final de cada grupo de palavra normal, há a reprodução de tablas fonéticas, as quais eram aplicadas com o objetivo de que as crianças treinassem e revisassem as sílabas derivadas dos grupos de palavras estudados. Os autores Zarilli e Soriano (1946), ao estudarem as metodologias utilizadas no Uruguai para o ensino da leitura, destacam que a inserção das tablas fonéticas em ¿Quieres Leer? foi realizada em edições posteriores à 
primeira, com o intuito de substituir os carteles, que haviam caído em desuso, o que, provavelmente explica a ausência dessas tabelas na edição de 1905.

A Queres Ler?, por sua vez, apresenta, logo nas páginas inicias, o prólogo redigido por José Henriques Figueira e o parecer de Antonio Henriques de Casaes. Após o índice, ao final do livro, um texto intitulado Instruções práticas sobre a didática da leitura no primeiro ano escolar (QUERES LER?, 1929, p. 119-125), sendo esse uma tradução da redação apresentada na versão uruguaia de 1905, e um texto denominado Novas orientações da educação, que expõe algumas regras para alcançar os resultados esperados com o uso da obra (QUERES LER?, 1929, p. 125-127).

Destacada a proposta apresentada no livro e a estrutura geral das cartilhas, bem como as especificidades identificadas nas duas edições de ¿Quieres Leer? e na versão de Queres Ler?, passamos, na seção seguinte, à discussão das orientações acerca do ensino da escrita, mais especificamente sobre os diferentes tipos de letras a ser ensinados durante o processo de aprendizagem inicial da escrita.

\section{As orientações para o ensino da escrita: os diferentes tipos de letras a serem ensinados}

Como exposto na seção anterior, as três edições analisadas neste texto possuem os mesmos princípios pedagógicos e a mesma estrutura e/ou organização. Desse modo, ainda que algumas especificidades caracterizem as diferentes versões é possível observar, no que tange ao ensino da escrita, que a proposta permanece a mesma, ou seja, ensinar a escrita simultaneamente com a leitura.

No entanto, ao mesmo tempo, também é perceptível que cada uma das edições apresenta as orientações específicas para o ensino da escrita e dos diferentes tipos de letras em partes distintas do livro. A versão uruguaia de 1905 e a gaúcha de 1929, por exemplo, explicitam tais informações nas notas explicativas que acompanham cada lição e na seção ao final da obra, ao expor os procedimentos e o "passo a passo" do método a ser desenvolvido. A edição uruguaia de 1931, contudo, apresenta tais orientações ao reproduzir, no início da obra, uma série de instruções, exercícios e movimentos preparatórios para a escrita e para o traçado dos diferentes tipos de letras, quais sejam: (i) a imagem de uma menina chamada Alicia e a descrição de uma postura corporal considerada como a mais adequada para o ato de escrever; (ii) quatro maneiras aceitáveis de segurar o lápis para escrever; (iii) uma tabla numérica com exercícios de pontos, linhas e figuras, considerados como o primeiro passo para a leitura e para a escrita de palavras e frases; (iv) a representação de dez movimentos musculares 
preparatórios para a escrita. Vale mencionar que esses exercícios são acompanhados de um texto intitulado Sugestiones para la enseñanza de la escritura corriente en el $1^{o}$ y $2^{o}$ ano de las escuelas primarias, que também não aparece na versão gaúcha e na edição uruguaia de 1905. Algumas dessas orientações e exercícios podem ser observados na imagem exposta a seguir:

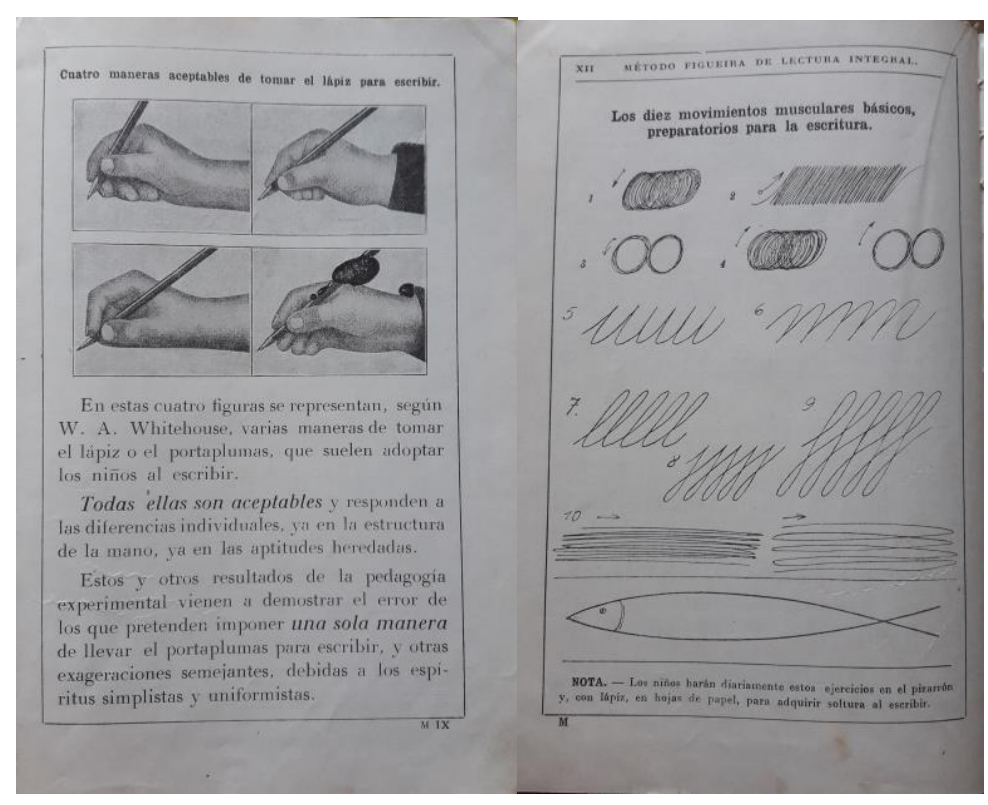

Figura 1 - Orientações para o ensino da escrita.

Fonte: ¿Quieres Leer?, 1931, p. IX e XII.

Nota-se, desse modo, que há, desde as primeiras páginas da ¿Quieres Leer? (1931), orientações teóricas e ilustrativas de procedimentos que os/as professores/as deveriam adotar para o ensino da escrita em sala de aula como, por exemplo, aceitar o uso de diferentes maneiras de a criança segurar o lápis no ato de escrever. As orientações nesse sentido explicitavam que o/a professor/a deveria ter presente que:

[...] hay varias maneras buenas de tomar el lápiz y el portaplumas para escribir [...] Los dedos pulgar, índice y mayor son los dedos de prensión y para escribir. Los dedos meñique y anular, generalmente, son los dedos de apoyo y condución de la mano. El antebrazo, cerca del codo, ofrece un punto de rotación a manera de eje, para los movimientos de progresión de la escritura. (¿QUIERES LEER?, 1931, p. XIII, grifos do original).

Quanto aos movimentos musculares básicos, é destacado nas orientações a importância de realizar o treino diário de alguns desses movimentos para adquirir a habilidade de escrita com "soltura". Ressalta-se que além de serem reproduzidos no início do livro de 1931, esses exercícios são apresentados novamente nas cinco primeiras lições da cartilha juntamente com o ensino das vogais, sendo que cada uma das lições apresenta o respectivo 
movimento utilizado para traçar determinada letra. Essa estratégia demonstra a intenção do autor em reforçar a importância desses movimentos para a escrita rápida e clara, especialmente a letra cursiva como se verá no decorrer do texto.

É interessante salientar que, como identificado em estudos anteriores, a adaptação gaúcha não conserva nas suas lições e notas explicativas os movimentos musculares preparatórios considerados necessários para a escrita, tampouco as orientações referentes a esse aspecto são enfatizadas no decorrer da obra (MICHEL; PERES; SILVEIRA, 2017). Raras vezes é feita menção a eles, e quando as autoras/adaptadoras o fazem, é com caráter sugestivo. O mesmo ocorre na edição uruguaia de 1905, uma vez que a referida versão a qual se teve acesso não apresenta a reprodução de tais movimentos, somente raras citações salientando a importância desses exercícios.

Essa ressalva indica uma diferença significativa entre as próprias edições uruguaias e, ainda, entre elas e a versão gaúcha no que tange à maneira como os/as professores/as deveriam conduzir o processo inicial do ensino da escrita. Elucida-se, dessa maneira, um rigor mais intenso nas orientações uruguaias, especialmente na publicação de 1931, para o treino gráfico, para os movimentos da escrita e quanto à postura necessária para ler, pois se acreditava que os mesmos eram indispensáveis para "adquirir soltura y flexibilidade para escribir” (¿QUIERES LEER?, 1931, p. XIII). Nesse sentido, questiona-se: a exclusão em relação à obra uruguaia de 1931 desses exercícios preparatórios e dessas orientações na versão gaúcha estaria articulada a uma opção pedagógica das autoras que adaptaram a obra? Estaria relacionada aos recursos econômicos da editora Selbach (responsável pela edição gaúcha)? Ou ainda, dever-se-ia às limitações impostas pelos recursos gráficos-editoriais da editora? Quanto ao acréscimo dessas orientações nas versões uruguaias posteriores à de 1905 questiona-se e indica-se a relevância de aprofundamento acerca das práticas pedagógicas, das discussões e do contexto uruguaio que aludiram essa modificação nas publicações de José Henriques Figueira.

Todavia, vale ressaltar que, embora esse rigor referente aos movimentos musculares não tenha sido reproduzido e indicado como um procedimento a ser realizado para a preparação da escrita na versão gaúcha há, nas notas que antecedem cada parte de Queres Ler? (1929), certa preocupação, por parte das autoras, em enfatizar de forma explícita a necessidade de as crianças realizarem exercícios repetitivos e de treinarem o traçado das letras, uma vez que "os exercícios de repetição dirigidos com inteligência têm grande valor educativo" (QUERES LER?, 1929, p. XVIII). Como exemplo são citados os exercícios de cópia e de ditado, os quais são também considerados fundamentais para o desenvolvimento da 
leitura e da escrita no método empregado nas edições uruguaias e, portanto, mantidos na adaptação das professoras rio-grandenses.

Especificamente acerca das orientações sobre os diferentes tipos de letras destaca-se que é perceptível tanto nas notas gerais e nas explicativas como na configuração das páginas da cartilha o ensino de dois tipos de letras: a de imprensa e a manuscrita, ainda que elas sejam nomeadas de maneira distintas: nas duas edições de ¿Quieres Leer? foram identificadas as expressões "ensino das letras de imprensa e cursiva" (1931, p. 10), "imprensa e de "mão"” (1905, p. 96), e "caracteres manuscritos” (1905, p. 117); na edição gaúcha é utilizada a designação "letra de forma e manuscrita" (1929, p. IX) e "letra de imprensa e cursiva" (1929, p. 1). Considerando que as diferentes expressões são empregadas como sinônimos, ressalta-se que no decorrer deste texto serão utilizadas as denominações letra de imprensa e letra manuscrita, por serem as mais recorrentes nas cartilhas.

O ensino simultâneo dessas duas tipologias de letras é contínuo em toda a obra, sendo intensificado em cada lição por meio da configuração de página assumida pelo autor. $\mathrm{Na}$ mesma, "Cada palavra básica é representada com a imagem que a objectiva, e escripta em seguida, em letra de fôrma e em letra manuscripta [...]" (QUERES LER?, 1929, p. XI). Além da palavra normal, também são apresentadas as sílabas que as compõem, assim como palavras derivadas dessas sílabas. A referida configuração de página pode ser observada na ilustração apresentada a seguir:

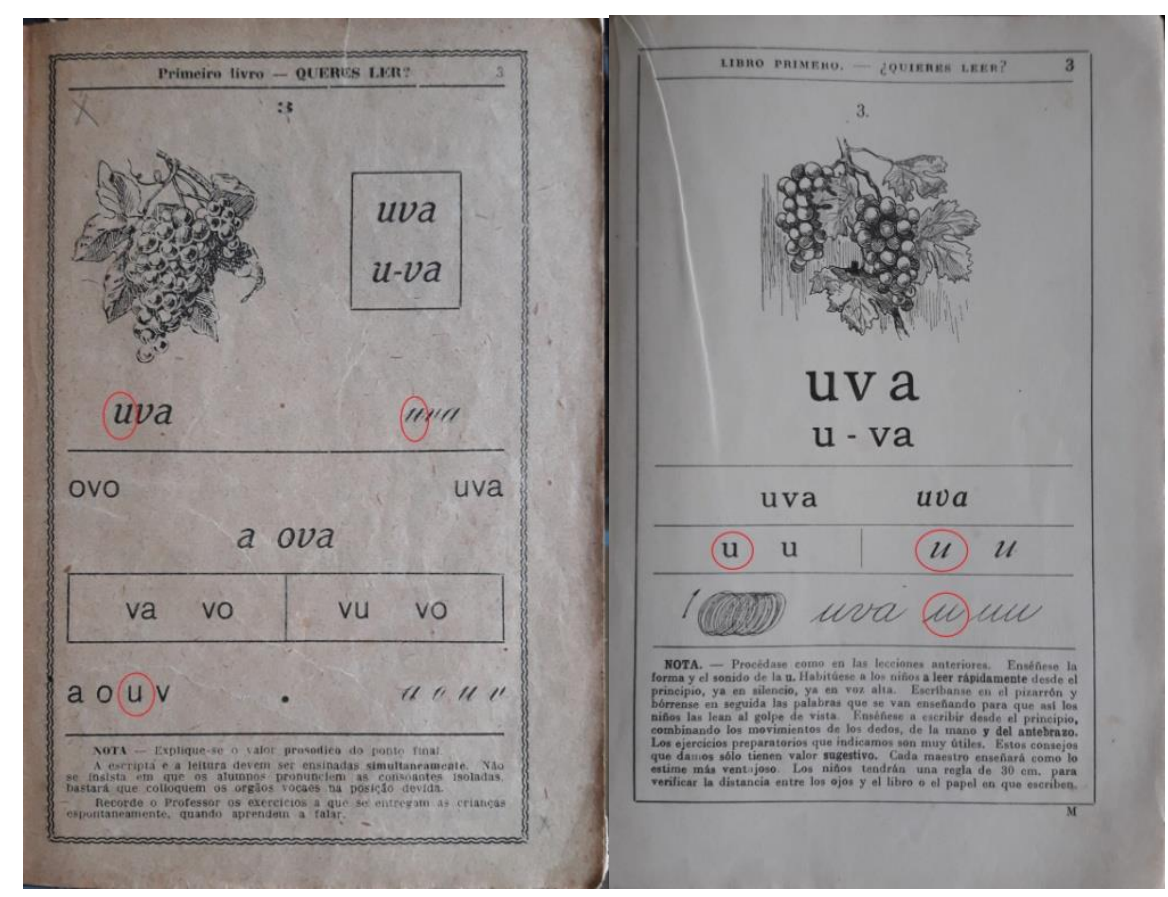

Figura 2 - Lição da uva.

Fonte: Queres Ler?, 1929, p. 3 e ¿Quieres Leer?, 1931, p. 3. 
Constata-se, a partir da figura apresentada, o ensino simultâneo das letras do tipo imprensa e manuscrita em todas as lições. Como referido anteriormente, também se evidencia especialmente na configuração de página da edição uruguaia de 1931, ao lado da "palavra normal" - uva - redigida em letra do tipo manuscrita, o movimento muscular básico necessário para a escrita da letra U. A seta para cima, que acompanha o desenho do movimento, indica o traçado a ser realizado para a escrita da letra no tipo cursiva.

Sobre o ensino desses dois tipos de letras na obra (manuscrita e de imprensa), José H. Figueira destaca:

No importa que los niños aprendan varios caracteres de letra. Esto, dentro de ciertos limites, será provechoso y dará más variedade a los ejercícios de escritura. Los niños, poco a poco, irán eligiendo, automaticamente, el carácter de letra que mejor se ajusta a la estructura de su mano, la cual suele presentar variaciones individuales importantes que modifican la manera de escribir y aún la misma escritura. (QUIERES LEER?, 1931, p. XIII).

Para o trabalho pedagógico do/a professor/a é indicado nas três edições que o/a mesmo/a deveria, utilizando-se do quadro-negro, inicialmente apresentar a letra manuscrita e em seguida a letra de imprensa. Para tanto, há a sugestão de propor aos alunos iniciantes o exercício de "escrever no ar com o dedo", tanto de olhos abertos quanto fechados, para assim treinar a escrita sem o desperdício de papel. Além dessas atividades, também é recorrente a preocupação de que as crianças fossem incentivadas a identificar as divergências no traçado dos dois tipos de letras, buscando entre elas as suas semelhanças e as suas diferenças. Para isso, ao final das três primeiras partes da cartilha são reproduzidos os alfabetos (na edição gaúcha) e o alfabeto e palavras (na versão uruguaia) com caracteres de imprensa e manuscritos. As orientações impressas no livro possibilitam afirmar que esses exercícios tinham a intenção de revisar os conteúdos trabalhados em cada parte da cartilha, pois segundo consta na obra, somente com o domínio desses saberes, as crianças poderiam avançar para a última parte.

Observa-se, ainda, como assinalado em vermelho na Figura 2, que nas três edições o ensino dos dois tipos de letras seguia diferentes estilos. Conforme consta na segunda seção deste texto e como é demonstrado na imagem referida, na segunda e na terceira parte da cartilha, as letras minúsculas e maiúsculas eram ensinadas no estilo inglês, itálico e romano (QUERES LER?, 1929, p. 117). Desse modo, como evidencia o exemplo da Figura 2, a letra U é apresentada na lição da cartilha nos formatos de imprensa vertical e inclinada e no formato manuscrito inclinado. 
Assim como nas lições, os alfabetos e as palavras reproduzidas ao final de cada parte da cartilha também eram apresentados nos dois tipos de letra (imprensa e manuscrita), com suas variações (maiúscula e minúscula) e, ainda, em diferentes estilos seguindo as orientações dos modelos caligráficos (vertical e inclinado), como pode ser observado na ilustração a seguir:

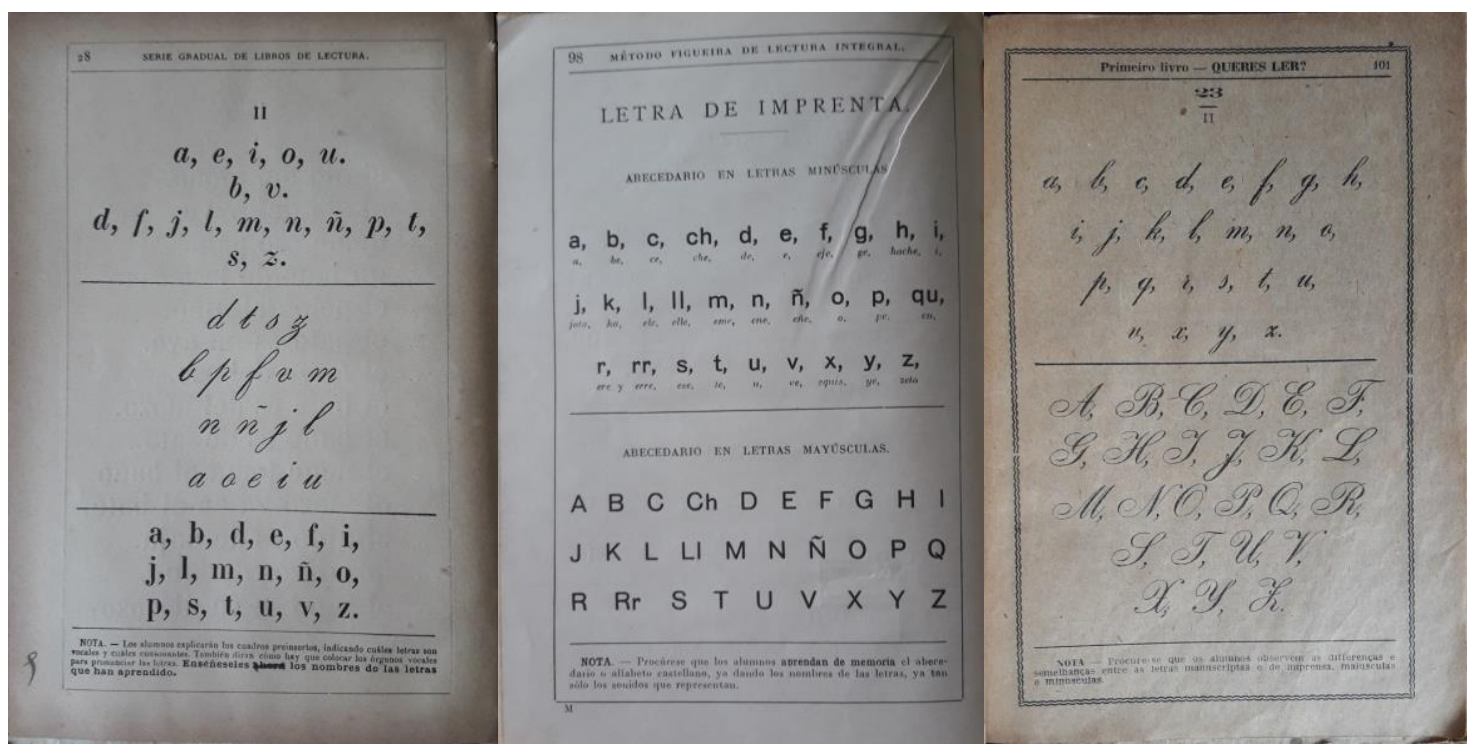

Figura 3 - Alfabetos.

Fonte: ¿Quieres Leer?,1905, p.28; ¿Quieres Leer?, 1931, p. 98; Queres Ler?, 1929, p. 101.

Na primeira lição exemplificada ainda não aparece o alfabeto completo, somente as letras que foram trabalhadas até o momento no livro, com ênfase para a versão minúscula das letras do tipo imprensa e manuscrita. No entanto, o traçado da letra de imprensa é realizado no modelo vertical e também levemente inclinado. Na segunda lição, retirada da edição de 1931, há o registro do alfabeto completo no tipo de letra de imprensa nas variações maiúscula e minúscula, no modelo vertical. Na terceira lição, extraída da adaptação gaúcha, o destaque está na letra do tipo manuscrita, nas variações maiúscula e minúscula, sendo em ambos os casos com inclinação.

O ensino dos diferentes modelos caligráficos (vertical e inclinado) e a opção por parte do aluno por um deles em sua escrita é reforçado na versão gaúcha à medida que as autoras indicam no final da cartilha, no tópico Instrucções Praticas, que o mestre registre no quadro-negro a palavra a ser ensinada "[...] com boa letra vertical ou um pouco inclinada" orientando, logo a seguir, que as crianças também façam o mesmo em seus cadernos: "Os alumnos farão com letra manuscripta vertical ou um pouco inclinada [...]” (QUERES LER, 1929, p. 122, 1929). 
Esse trecho demonstra que a escrita do professor é exemplo para os alunos. Em razão disso, o destaque é dado para a boa letra, mas também para a ênfase nas variações dos diferentes tipos e modelos de letras, o que implica na inferência de que possivelmente existisse, na obra, a preocupação em preparar os alunos para as diversidades de escritas encontradas na sociedade.

Contudo, ainda que essa hipótese seja lançada e que o autor destaque a importância de o aluno conhecer diferentes tipos de letras (manuscrita e de imprensa) e seus diferentes modelos caligráficos (vertical ou inclinado) e que, posteriormente, possa eleger aquele que melhor se adapte, é notável ao folhear as três edições que, na obra, a ênfase no ensino é para a letra tipo imprensa, no modelo vertical, ou seja, a opção pelo ensino de uma escrita higiênica, clara e rápida, máximas essas atribuídas ao modelo caligráfico vertical. Essa escolha do autor pode ser evidenciada, no excerto apresentado a seguir:

\footnotetext{
Hemos adoptado la letra anglo-americana de trazos de igual grosor. Este carácter de letra puede considerarse hoy como el tipo normal de la letra moderna comercial (higiénica, clara, rápida). Aunque no se trata de caligrafia (bella escritura) la letra que presentamos es hermosa. En las escuelas avanzadas de Europa, y, sobre todo en los Estados Unidos y en Inglaterra, no se enseña en las escuelas la letra inglesa clásica. Esta sólo se usa en las tarjetas, diplomas, etc. La práctica dominante consiste en enseñar una letra fácil, clara y rápida en la que se suprime todo rasgo inútil (¿QUIERES LEER?, 1931, p. XIII, grifos do original).
}

De acordo com Vidal e Gvirtz (1998), até o começo do século XX o modelo inclinado era o mais recorrente no país, mas a partir de 1910 o modelo vertical ganha espaço, especialmente, pela influência européia, sendo reconhecido, portanto, como calligraphia franceza (MARTÍNEZ; BOYNARD, 2005); ou ainda, segundo Fetter (2011), recebendo a denominação de escrita direita, se estabelecendo com mais efetividade nos espaços educacionais por meados dos anos de 1920 e permanecendo por um longo período na escola durante o século XX.

Os defensores do modelo inclinado, o consideravam mais adequado para o trabalho comercial e industrial devido à suposta velocidade, ou seja, quanto mais inclinada a letra, mais rápida seria a escrita. No entanto, quanto maior a inclinação menos legível se tornava a escrita, por isso esse modelo acaba sendo criticado para o ensino nas escolas. Já os defensores do modelo vertical alegavam que "[...] o desenho das letras ficava mais fácil, uniforme e mais legível”, definindo-a como um "tipo de letra, que vulgarmente se chama letra em pé, além de fácil, é rápido, econômico e higiênico" (FARIA FILHO, 1998, p. 138). Além disso, consideravam a escrita vertical um modelo higiênico, "posto que afirmavam que a postura corporal indicada por esse modelo evitava deformidades físicas" (VIDAL; ESTEVES, 2003, 
p. 121). Era a defesa da famosa trilogia do período "posição direita, caderno direito, escrita direita" (Ibidem, p. 120).

A esse respeito é interessante destacar que no começo do século XX, no Brasil, a discussão sobre o ensino da escrita estava pautada nos modelos caligráficos, ou seja, que apresentavam técnicas consideradas ideais para a postura corporal como, por exemplo, a maneira correta de sentar, de posicionar os braços nas classes, de segurar o lápis, entre outras, que permitiam que o ato de escrever fosse executado de maneira eficiente e sem prejudicar a saúde das crianças. Assim, nesse período destaca-se a ênfase nos modelos inclinado e vertical. No entanto, na década de 1930 com os estudos de Orminda Marques ${ }^{11}$, no Rio de Janeiro, o modelo caligráfico muscular começa a ganhar espaço no cenário educacional.

A caligrafia muscular, por sua vez, defendida no Brasil pela professora Orminda Marques, foi desenvolvida por meio de uma experiência na escola primária do Instituto de Educação do Distrito Federal (RJ) e consistia na "caligrafia baseada nos movimentos ritmados do antebraço; letra inclinada e sem talhe" deixando a mão mais livre para a escrita (MARQUES, 1936, p. 11). Essa concepção encontrava respaldo na justificativa de que na "escrita temos que ganhar tempo. Tudo marcha rapidamente. O ritmo a que temos que obedecer vivendo a vida moderna é sempre e cada vez mais acelerado" (MARQUES, 1936, p. $18)$.

É interessante observar que mesmo a caligrafia muscular tendo uma repercussão inicial no Rio de Janeiro a partir da década 30 do século XX, e no Rio Grande do Sul entre os anos de 1930 a 1960 (MONTEIRO, 2012), ela já se fazia presente, de certa forma, na versão uruguaia, especialmente na edição de 1931, por meio do texto Sugestiones para la enseñanza de la escritura corriente en el $1^{\circ}$ y $2^{\circ}$ ano de las escuelas primarias, uma vez que há nele as seguintes orientações referente aos tempos de escrita de cada uma das letras, por exemplo:

Dedíquese todos los dias 10 minutos a los ejercícios de escritura simultánea y rítmica; es decir: contando el maestro en voz alta los tiempos requeridos para la formación de las letras. Así, en la letra b, se contarán 4 tiempos. [...] Permitase que los niños repasen cada letra unas 5 veces seguidas, usando, al efecto, papel transparente o de calcar, que aplicarán sobre los modelos que oferecemos en este libro. Estos ejercícios sirven para coordenar los numerosos movimentos musculares

\footnotetext{
${ }^{11}$ Orminda Marques era professora da escola de aplicação da Escola Normal do então Distrito Federal, Rio de Janeiro e foi responsável por um trabalho de experimentação com escrita na escola primária, sob a orientação do professor Lourenço Filho diretor do Ensino Normal desta mesma instituição. Para saber mais, ver Monteiro (2012), que em sua Dissertação de Mestrado (PPGEdu/UFRGS) analisa a repercussão das obras de Orminda Marques no Rio Grande do Sul. Para isso a autora consultou especialmente a Revista do Ensino (RS) e os comunicados do Centro de Pesquisas e Orientação Educacionais do Rio Grande do Sul (CPOE/RS).
} 
que intervirnen en el acto de escribir. (¿QUIERES LEER?, 1931, p. XIII, grifos do original).

Embora, como já frisado, a versão gaúcha não tenha conservado tais orientações não é pouco provável que as professoras gaúchas tenham tido acesso a elas, assim como provavelmente, estavam envolvidas com as discussões vigentes no Rio Grande do Sul sobre o ensino da escrita muscular difundida por meio do trabalho de Orminda Marques.

Pode-se dizer, ainda, que a opção do autor da obra, José H. Figueira, pelo ensino da letra do tipo imprensa, com modelo vertical, pode ser corroborada especialmente nas duas últimas partes da cartilha, as quais trazem lições específicas com frases e textos. Embora as frases estejam presentes desde a primeira parte do livro é na terceira e na quarte parte que elas são enfatizadas, pela complexidade da leitura e da escrita que a criança já alcançou. Nessas duas partes do livro a predominância é para o ensino da letra do tipo imprensa, uma vez que tanto as frases como os textos são reproduzidos quase que exclusivamente nessa tipologia. A escrita com a letra manuscrita aparece nas lições, no entanto, na terceira parte, por exemplo, do total de 10 a 15 frases que constituem cada uma das lições, as frases em letra do tipo manuscrita não ultrapassam a quantia de três, sendo, inclusive, essa uma situação encontrada em Queres Ler?, pois, geralmente, nas outras duas edições é reproduzida somente uma frase com esse tipo de letra, como pode ser observado na figura a seguir:

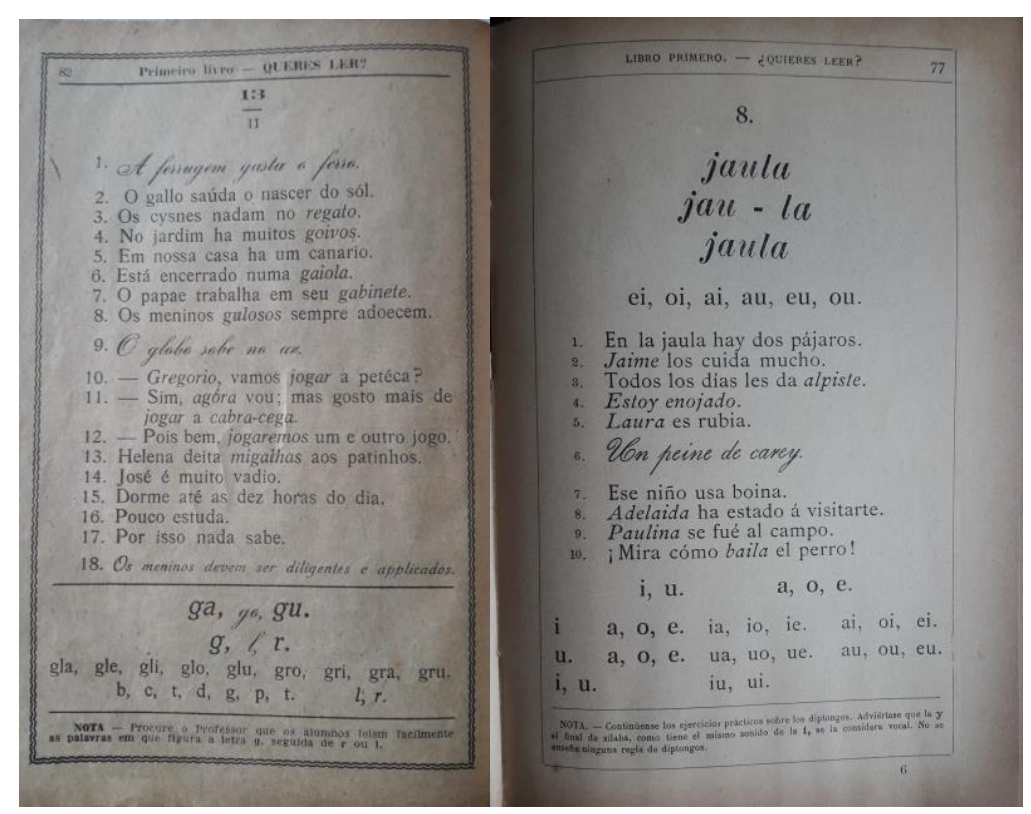

Figura 4 - Lições com frases.

Fonte: Queres Ler?, 1929, p. 82; Quieres Leer?,1905, p.77.

Ressalta-se, desse modo, que, de maneira geral, nos três exemplares analisados a maioria das frases aparece escrita seguindo o modelo caligráfico vertical. O fato de a Queres 
Ler? ser a versão que apresenta o maior número de lições com frases em caracteres manuscritos em comparação às edições uruguaias, é interessante à medida que evidencia a compreensão das autoras acerca do processo do ensino da escrita e dos tipos de letras.

Da mesma maneira, a quarta parte da obra também tem predominância de lições com a letra do tipo imprensa, no modelo vertical, sendo somente um dos textos reproduzidos com a letra do tipo manuscrita. O texto intitulado Carta é o único que mantém inalterada a tipologia da letra nas três edições.

A partir do exposto no texto é possível levantar a hipótese de que a ênfase no ensino da letra do tipo imprensa, seguindo o modelo vertical, tenha ocorrido, pois conforme já mencionado, era ele que estava em voga nas primeiras décadas do século XX, período em que o autor atualiza a Quieres Leer? e época em que as professoras gaúchas adaptam essa obra para o português e a utilizam nas aulas públicas do Rio Grande do Sul. Segundo Fetter (2011), esse tipo de letra atendia as necessidades dos psicólogos e pedagogos que não estavam preocupados em desenvolver apenas a coordenação motora das crianças, esses pensadores defendiam acima de tudo a escrita legível desde o princípio, uma vez que ela possibilitava também quebrar "as barreiras entre a leitura e a escrita, abolindo as diferenças entre as formas das letras de cada uma, além de permitir mais efetividade aos métodos simultâneos" (FETTER, 2011, p.184).

Como se observa, os princípios pedagógicos das versões uruguaia e gaúcha estavam em consonância com os discursos vigentes à época no Brasil sobre o ensino da escrita e dos diferentes tipos de letras, uma vez que a mesma apresentava desde as primeiras lições o ensino tanto da letra do tipo manuscrita como de imprensa e orientava, ainda, que os/as professores/as investissem em técnicas e exercícios que possibilitassem o treino da escrita inclinada, vertical e/ou muscular.

Desse modo, destaca-se que a discussão dos modelos caligráficos (vertical, inclinado e muscular) em voga no período se faziam presentes nas orientações da cartilha para o ensino da escrita em geral e para o ensino dos diferentes tipos de letras. Assim, não é hipótese infundada que o fato de essa discussão estar em voga no Brasil tenha contribuído para a aprovação do uso de Queres Ler? nas escolas públicas do Rio Grande do Sul no final da década de 20 do século XX.

\section{Conclusão}

O objetivo principal deste texto é cotejar as orientações apresentadas aos professores sobre o ensino da escrita, enfatizando os tipos de letras presentes na obra didática uruguaia 
¿Quieres Leer?, de José Henriques Figueira, e na adaptação Queres Ler?, feita por Olga Acauan e Branca Diva Pereira de Souza.

A referida obra foi utilizada por um longo período tanto no Uruguai como no Rio Grande do Sul para o ensino da leitura e da escrita na fase inicial da escolarização, sendo adaptada pelas duas professoras gaúchas mencionadas, imediatamente após a missão de estudos que realizaram ao Uruguai entre os anos de 1914 e 1916.

A temática escolhida para análise ocorreu em virtude de outros estudos em desenvolvimento, mas também pela relevância da temática e pela ínfima discussão realizada no campo da História da Educação sobre o ensino dos diferentes tipos de letras no início do século XX. Considerando, portanto, que artefatos da cultura material como, por exemplo, os livros escolares utilizados na fase inicial da escolarização expressam parte das discussões do período acerca do ensino da escrita, optamos por analisar uma obra didática que teve significativa circulação e uso nas escolas públicas gaúchas no século XX. Para tanto, analisaram-se três exemplares do título ¿Quieres Leer?, sendo duas edições uruguaias (1905; 1931) e uma edição gaúcha (1929).

As análises possibilitaram identificar que as três edições possuem a mesma proposta, isto é, ensinar a escrita simultaneamente com a leitura. Contudo, foi possível observar que a edição de 1931 ressalta, por meio de orientações teóricas e ilustrativas, desde as primeiras páginas a relevância de exercícios musculares básicos, os quais são considerados como preparatórios e fundamentais para uma escrita rápida e legível. Tais exercícios são reproduzidos novamente nas primeiras lições do livro para acompanhar o ensino das vogais e os respectivos movimentos necessários para a escrita da letra no tipo manuscrita. Essas orientações e movimentos, no entanto, não aparecem na ¿Quieres Leer? de 1905 e foram suprimidas na Queres Ler?, o que indica uma diferença entre as edições uruguaias e entre elas e a edição gaúcha no que tange à maneira como os/as professores/as deveriam conduzir o processo inicial do ensino da escrita.

Especificamente sobre o ensino dos diferentes tipos de letras, os dados coletados permitem afirmar que há, na obra, a intenção de ensinar simultaneamente a letra do tipo manuscrita e de imprensa em diferentes modelos caligráficos (vertical e inclinado). Não é pouco provável que o ensino da escrita, enfatizando as variações dos diferentes tipos e modelos de letras, estivesse articulado à preocupação do método em preparar os alunos para as diversidades de escritas encontradas na sociedade. Todavia, embora esteja explícito, na obra, a compreensão do autor de que é relevante que as crianças aprendam vários caracteres de letras, é perceptível ao mesmo tempo a predominância pelo ensino da letra do tipo 
imprensa, no modelo vertical, o que se corrobora por meio do uso contínuo dessa tipologia de letra em várias partes da cartilha, especialmente na terceira e na quarta parte do livro quando são apresentadas as lições com frases e textos.

Da mesma maneira, a opção de José H. Figueira pelo ensino do modelo caligráfico vertical, caracterizado por uma escrita higiênica, clara e rápida, está vinculada às discussões do período, uma vez que a ênfase no ensino da letra do tipo imprensa, no modelo vertical, estava em voga nas primeiras décadas do século $\mathrm{XX}$.

Desse modo, destaca-se que a discussão dos modelos caligráficos (vertical, inclinado e muscular) em voga no período se faziam presentes nas orientações da cartilha para o ensino da escrita em geral e para o ensino dos diferentes tipos de letras. Assim, não é hipótese infundada que o fato de essa discussão estar em vigor no Brasil tenha contribuído para a aprovação do uso de Queres Ler? nas escolas públicas do Rio Grande do Sul no final da década de 20 do século XX.

Além disso, a partir dos dados, destaca-se a importância de pesquisar artefatos da cultura material escolar, uma vez que eles nos permitem observar as concepções teóricas e metodológicas dos autores, especialmente nesse caso, para o ensino da escrita presentes em livros escolares utilizados na fase inicial da escolarização, assim como as variações e atualizações que os mesmos realizam em virtude das demandas sociais e pedagógicas de um determinado período.

\section{Referências}

ACAUAN, O.; SOUZA, B.D.P. Queres ler?: primeiro livro. $3^{\mathrm{a}}$ ed. Porto Alegre: Livraria Selbach de J. R. da Fonseca \& Cia. 1929.

ARAÚJO, Orestes. Historia de la escuela uruguaya. Montevideo: El Siglo Ilustrado, 1911.

ARRIADA, E.; TAMBARA, E. Uma missão pedagógica ao Uruguai: Aprendizagem, métodos, princípios. In: ASPHE, 19ª , Pelotas, Anais... Pelotas-RS, 2013.

BASTOS, M.H. C. Uma biografia dos manuais de história da educação adotados no Brasil (1860-1950). In: VI Congresso Luso-Brasileiro de História da educação, 2006, Uberlândia. Percursos e Desafios da pesquisa e do ensino em História da Educação. Uberlândia: Editora da UFU, 2006.

CALKINS, N. Lições de coisas. Tradução Rui Barbosa. Rio de Janeiro: Ministério da Educação e Saúde, 1956. (Obras completas, v. 13, t. 1).

FARIA FILHO, L.M. Cultura e Prática Escolares: escrita, aluno e corporeidade. In: Caderno de Pesquisa, n.103, março de 1998. 
FETTER, S; LIMA, E; LIMA, G. O Ensino da Escrita Manual no Brasil: Dos Modelos Caligráficos à Escrita Pessoal no Século XXI In: BOCC. Biblioteca On-line de Ciências da Comunicação, v. IV, p. 1-31, 2010.

FETTER, S. Modelos caligráficos na Escola Brasileira: uma história do Renascimento aos nossos dias. 2011. 260 f. Dissertação (Mestrado em Design) - Escola Superior de Desenho Industrial, Universidade do Estado do Rio de Janeiro, Rio de Janeiro, 2011.

FIGUEIRA, J. H. ¿Quieres Leer?. Casa A. Barreiro y Ramos. S.A. Montevideo. 1943. . ¿Quieres Leer?. Casa A. Barreiro y Ramos. S.A. Montevideo. 1905.

FIGUEIRINHA, A. Lições de Pedagogia. Porto/PT: Casa editora António Figueirinhas L.D.A 1927.

MARTÍNEZ, S.A.; BOYNARD, M.A.A.P.. Uso da imprensa periódica como estratégia de divulgação e reivindicação de novas práticas de escrita no Estado do Rio de Janeiro: Campos, 1914-1915. Universidade Estadual do Norte Fluminense Darcy Ribeiro, Campos, (2005).

MICHEL, C. A cartilha Queres ler?: difusão e circulação de um novo método para o ensino da leitura e da escrita no Rio Grande do Sul no início do século XX. In: PERES, E.; RAMIL, C.A. (Orgs.) Produção e circulação de livros didáticos no Rio Grande do Sul nos séculos XIX e XX. Curitiba: Editora Appris, 2018. p. 81-104.

MICHEL, C. Missão de estudos ao Uruguai: mudanças no sistema de ensino do Rio Grande do Sul (1913-1927). 2017. 283 f. Tese (Doutorado em Educação) - Faculdade de Educação, Universidade Federal de Pelotas, Pelotas. 2017.

MICHEL, C.B.; PERES, E.; SILVEIRA, A.A. As cartilhas ¿Quieres Leer? e Queres Ler?: recorrências e diferenças nas notas de orientações aos professores. Educação em Foco, ano 20, n. 32, p. 145-165, set/dez. 2017. ISSN 2317-0093. Disponível em: http://revista.uemg.br/index.php/educacaoemfoco/article/view/1306 Acesso em: 26 dez. 2018.

MICHEL, C. B.; ARRIADA, E.; PERES, E.. Os livros de leitura ¿Quieres leer? e Queres ler?: do Uruguai para o Rio Grande do Sul. Momento. v. 24, n. 1, p. 151-170, jan./jun. 2015. ISSN 2316-3100. Disponível em: http://revista.uemg.br/index.php/educacaoemfoco/article/view/1306. Acesso em: 26 dez. 2018.

MONTEIRO, C. A escrita na escola primária: repercussões da obra de Orminda Marques nas décadas de 30 a 60 do século XX. 2012. 120 f. Dissertação (Mestrado em Educação) Faculdade de Educação, Universidade Federal do Rio Grande do Sul, Porto Alegre. 2012.

NÓVOA, A.; SCHRIEWER, J. A difusão mundial da escola - alunos, professores, currículo, pedagogia. Lisboa: EDUCA, 2000.

ORMINDA, M. A escrita na escola primária. São Paulo: Melhoramentos, 1936. 
PERES, E. O ensino da linguagem na escola pública primária gaúcha no período da renovação pedagógica (1930 - 1950). In: PERES; Eliane; TAMBARA, Elomar. (org.). Livros escolares e ensino da leitura e da escrita no Brasil (séculos XIX - XX), Pelotas/RS: Seiva, 2003.

PERES, E. A produção e o uso de livros de leitura no Rio Grande do Sul: Queres Ler? e Quero Ler. História da Educação, Pelotas, RS, v. 3, n. 6, p. 89-103, out. 1999. ISSN 22363459. Disponível em: https://seer.ufrgs.br/asphe/article/view/30260. Acesso em: 26 dez. 2018.

RIO GRANDE DO SUL. A Federação, Jornal Diário, 1913, p. 5.

TRINDADE, Iole. A invenção de uma nova ordem para as cartilhas: ser maternal, nacional e mestra: queres ler?. 2001. 524f. Tese (Doutorado em Educação) - Faculdade de Educação, Universidade Federal do Rio Grande do Sul, Porto Alegre. 2001.

VALDEMARIM, V. T. Método Intuitivo: os sentidos como janelas e portas que se abrem para um mundo interpretado. In: SOUZA, R. F., VALDEMARIM, V. T.; ALMEIDA, J. S. $O$ legado educacional do século XIX. Araraquara: UNESP, 1998.

VIDAL, D. G.; ESTEVES, I. L. Modelos caligráficos concorrentes: as prescrições para a escrita na escola primária paulista (1910-1940). In: PERES, E., TAMBARA, E. (org). Livros escolares e ensino da leitura e da escrita no Brasil (séculos XIX - XX), Pelotas/RS: Seiva, 2003.

VIDAL, D.; GVIRTZ, S. O ensino da caligrafia e a conformação da modernidade escolar: Brasil e Argentina, 1880-1940. In: Revista Brasileira de Educação, n.8, p. 13-30 mai/jun/jul/ago. $1998 . \quad$ Disponível em: http://anped.tempsite.ws/novo_portal/rbe/rbedigital/RBDE08/RBDE08_04_DIANA_E_SILV INA.pdf. Acessado em 07 jan. 2019.

ZARILLI; H.; SORIANO, R. A. Metodologia de la lectura. Desde el deletreo a la globalizacion. Montevideo: Talleres Gráficos Sur, 1946. 